\title{
The value of a new prognostic model developed by lymphocyte-monocyte ratio and platelet-monocyte ratio in peripheral T-cell lymphoma
}

\author{
Yan Zhang ${ }^{1,2+}{ }^{\prime}$, Yuanfei Shi ${ }^{2 \dagger}$, Huafei Shen ${ }^{2}$, Lihong Shou', Qiu Fang ${ }^{1}$, Xiaolong Zheng ${ }^{2}$, Mingyu Zhu ${ }^{2}$,

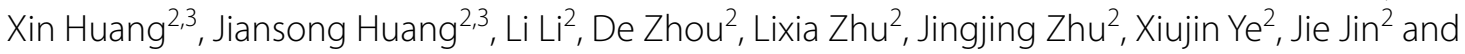 \\ Wanzhuo Xie ${ }^{2^{*}}$ (D)
}

\begin{abstract}
Peripheral T-cell lymphoma(PTCL) is a group of lymphoproliferative tumors originated from post-thymic T cells or mature natural killer (NK) cells. It shows highly aggressive clinical behaviour, resistance to conventional chemotherapy, and a poor prognosis. Although a few prognostic models of PTCL have been established in retrospective studies, some high-risk patients still can not be screened out. Therefor we retrospectively studied 347 newly diagnosed PTCL patients and assessed the prognostic role of lymphocyte-monocyte ratio (LMR) and platelet-monocyte ratio (PMR) in the complete response (CR) and survival of PTCL patients. Patients with $L M R \leq 1.68$ and PMR $\leq 300$ achieved a lower $C R$ rate and a poor survival. In multivariate analysis, $L M R \leq 1.68(H R=1.751,95 \% \mathrm{Cl} 1.158-2.647, \mathrm{p}<0.05)$ and $P M R \leq 300(H R=1.762,95 \% \mathrm{Cl} 1.201-2.586, \mathrm{p}<0.05)$ were independently associated with short survival. On this basis, a new prognostic model of PTCL was established to screen out high-risk patients. In our "Peripheral Blood Score (PBS)" model, three groups were identified at low risk (178 patients, 51.3\%, score 0), intermediate risk (85 patients, 24.5\%, score 1), and high risk ( 84 patients, $24.2 \%$, score 2), having a 1 -year OS of $86 \%, 55.3 \%$ and $22.6 \%$ ( $p<0.05$ ), and a 3-year OS of $43.4 \%, 20 \%$ and $13.1 \%(p<0.05)$, respectively. Optimal strategies for identifying high-risk patients with PTCL are urgently needed. Our new PBS model is simple, inexpensive and widely available to screen out the high risk patients.
\end{abstract}

Keywords: Peripheral T-cell lymphoma, Lymphocyte, Platelet, Monocyte, Prognosis, Tumor micro-environment, Immunity

\section{Introduction}

Peripheral T-cell lymphoma (PTCL) is a group of rare hematological malignancies with heterogeneous morphological and biological characteristics. The overall manifestations are high invasive, short survival and poor

\footnotetext{
*Correspondence: xiewanzhuo@zju.edu.cn

†Yan Zhang and Yuanfei Shi contributed equally to this work

2 Department of Hematology, College of Medicine, the First Affiliated

Hospital, Zhejiang University, No. 79 Qingchun Road, Hangzhou 310003, Zhejiang, China

Full list of author information is available at the end of the article
}

prognosis. The total incidence rate is $0.5-2$, per 100,000 persons per year, and account for about $10 \%$ of all nonHodgkin's lymphomas (NHL) in Western countries [1]. However, the incidence of PTCL in Asia is higher, accounting for $25-30 \%$ of NHL in China [2]. Nowadays, the internationally recommended first line therapy is still anthracycline-based chemotherapy. But the complete response (CR) rate after chemotherapy is only $40-60 \%$, with overall survival (OS) of $30-40 \%$. Most patients face the problem of short-term recurrence and the median OS of these patients without stem cell transplantation were 
only 5.5 months [3-5]. Once the disease relapses or progresses, patients will lose effective treatment measures.

According to the WHO classification, PTCL can be further divided into many pathological subtypes. The most common subtypes include PTCL not otherwise specified (PTCL-NOS), extra-nodal natural killer (NK)/T cell lymphoma, nasal type (ENKTL), angioimmunoblastic T-cell lymphoma (AITL), anaplastic lymphoma kinase positive anaplastic large cell lymphoma (ALK + ALCL) and anaplastic lymphoma kinase negative anaplastic large cell lymphoma (ALK- ALCL) [6]. In addition, there are some rare subtypes, such as monomorphic epitheliotropic intestinal T-cell lymphoma (MEITL), subcutaneous panniculitis like T-cell lymphoma (SPTCL), mycosisfungoides/Sezary's syndrome (MF/SS), Hepatosplenic T-cell lymphoma (HSTCL) and so on. Due to its rarity and heterogeneity, the prognosis of PTCL were less studied.

Over the past few decades, a number of prognostic models based mainly on clinical variables have been put forward, among which the International Prognostic Index (IPI) scoring model based on the data of patients with diffuse large B-cell lymphoma was earlier and more widely used on PTCL patients[3]. The Intergruppo Italiano Linfomi (now Fondazione Italiana linfomi, FIL) performed a large study on 385 patients diagnosed and treated in the 1990s and defined the Prognostic Index for PTCL-unspecified (PIT), in which age, ECOG, LDH level and bone-marrow involvement were independent predictors of OS in PTCL-NOS patients [7]. The PIT divided the patients into four different risk groups: low-risk (no adverse factors), intermediate ( 1 adverse factor), intermediate-high ( 2 adverse factors) and high (3-4 adverse factors) [7]. The 5-year OS were 62.3\%, 52.9\%, 32.9\% and $18.3 \%$, respectively $(\mathrm{P}<0.05)$. The PIT can stratify patients more effectively than IPI [7]. A common limitation of the above models is the complexity of their use.

Systemic inflammatory response and host immunity played an important role in promoting the clinical courses of tumors and determining the prognosis of tumor patients [8]. According to the previous studies, LMR was closely related to the prognosis of esophageal squamous cell carcinoma, malignant melanoma, bladder cancer and ovarian clear cell cancer [9-12]. Similarly, platelet count and PMR were closely related to the occurrence of acute exacerbation of chronic obstructive pulmonary disease, pulmonary embolism and prognosis of various tumors [13]. In hematological malignancies, LMR and PMR are also bound up with poor prognosis of diffuse large B-cell lymphoma (DLBCL) and Follicular lymphoma (FL) [14-16]. However, there are few reports about the response and prognosis of LMR and PMR in PTCL patients.
Here, we retrospectively analyzed 347 patients with primary PTCL in a single center and found that patients with $\mathrm{PMR} \leq 300$ and $\mathrm{LMR} \leq 1.68$ were closely related to poor response and low survival rate. On this basis, established a peripheral blood score (PBS) model for identification of high-risk PTCL patients. The patients were divided into low-risk, intermediate-risk and high-risk groups. 44 patients who met the enrollment Requirements in another center were substituted into the PBS model for verification. PBS model can distinguish some patients with poor prognosis.

\section{Materials and methods}

\section{Patients and characteristics}

This is a single center retrospective study. A total of 347 patients with PTCL newly diagnosed in the First Affiliated Hospital of Zhejiang University School of Medicine from January 2011 to October 2019 were included. The final observation time was January 2020, and the median follow-up time was 18 months (rang: 0-108 months). The inclusion criteria were as follows: (1) Age $\geq 15$ years; (2) The pathological diagnosis was consistent with PTCL; (3) Newly diagnosed and no chemotherapy before clinical data were collected; (4) Complete clinical data; (5) At least two cycles of treatment were given. Although the treatment plan were not completely unified, all the patients in our study received cyclophosphamide-doxorubicin-vincristine-prednisone (CHOP) or CHOP-like chemotherapy regimen, and all ENKTL patients were treated with chemotherapy combined with Pegaspargase. All procedures involving human participants in our study were conducted in accordance with the Helsinki declaration.

We collected the medical records, physical examinations, laboratory results, pathological reports and radiological results of these patients through electronic medical records, and re analyzed the clinical data of them. All baseline data are presented in Table 1. Followup was performed by making phone calls. The absolute counts of lymphocytes, monocytes and platelets were obtained from a standard complete blood count (CBC) performed at diagnosis. LMR was the absolute count of lymphocyte divided by the absolute count of monocyte. PMR was the ratio of platelet absolute count to monocyte absolute count. OS was defined as the time from diagnosis to death for any reasons or last follow-up.

\section{Cut-off value for LMR/PMR}

The optimal cut-off of LMR and PMR were obtained by calculating the area under the curve by receiver operating characteristic (ROC) curve analysis by taking survival as the state variable. 
Table 1 Characteristics of 347 patients with PTCL based on the LMR and PMR

\begin{tabular}{|c|c|c|c|c|c|c|c|}
\hline Characteristic & $\begin{array}{l}\text { Total } \\
(n=347)\end{array}$ & $\begin{array}{l}\mathrm{LMR} \leq 1.68 \\
(\mathrm{n}=127)\end{array}$ & $\begin{array}{l}\text { LMR }>1.68 \\
(n=220)\end{array}$ & $p$ value & $\begin{array}{l}P M R \leq 300 \\
(n=126)\end{array}$ & $\begin{array}{l}\mathrm{PMR}>300 \\
(\mathrm{n}=221)\end{array}$ & $p$ value \\
\hline Age & & & & 0.063 & & & 0.202 \\
\hline$<60$ years & $222(64.0)$ & $73(57.5)$ & $149(67.7)$ & & $75(59.5)$ & $147(66.5)$ & \\
\hline$\geq 60$ years & $125(36.0)$ & $54(42.5)$ & $71(32.3)$ & & $51(40.5)$ & $74(33.5)$ & \\
\hline Sex & & & & 0.482 & & & 0.289 \\
\hline Male & $229(66.0)$ & $87(68.5)$ & $142(64.5)$ & & 88(69.8) & $141(63.8)$ & \\
\hline Female & 118(34.0) & $40(31.5)$ & $78(35.5)$ & & $38(30.2)$ & $80(36.2)$ & \\
\hline IPI & & & & $<0.05^{*}$ & & & $<0.05^{*}$ \\
\hline $0-2$ & 154(44.4) & $29(22.8)$ & $125(56.8)$ & & $27(21.4)$ & $127(57.5)$ & \\
\hline $3-5$ & 193(55.6) & $98(77.2)$ & 95(43.2) & & 99(78.6) & $94(42.5)$ & \\
\hline ECOG & & & & $<0.05^{*}$ & & & $<0.05^{*}$ \\
\hline $0-2$ & $241(69.5)$ & $66(52.0)$ & $175(79.5)$ & & $64(50.8)$ & 44(19.9) & \\
\hline $3-5$ & 106(30.5) & $61(48.0)$ & $45(20.5)$ & & $62(49.2)$ & 177(80.1) & \\
\hline Stage & & & & $<0.05^{*}$ & & & $<0.05^{*}$ \\
\hline$|-| \mid$ & $65(18.7)$ & $1(0.8)$ & $64(29.1)$ & & $6(4.8)$ & $59(26.7)$ & \\
\hline||$|-| V$ & 282(81.3) & 126(99.2) & 156(70.9) & & 120(95.2) & $162(73.3)$ & \\
\hline B symptoms & & & & $<0.05^{*}$ & & & $<0.05^{*}$ \\
\hline Yes & 203(58.5) & $97(76.4)$ & $106(48.2)$ & & $94(74.6)$ & 109(49.3) & \\
\hline No & 144(41.5) & $30(23.6)$ & 114(51.8) & & $32(25.4)$ & $112(50.7)$ & \\
\hline Histological subtype & & & & 0.330 & & & $0.018^{*}$ \\
\hline PTCL,NOS & $111(32.0)$ & $45(35.4)$ & $66(30.0)$ & & $51(40.5)$ & $60(27.1)$ & \\
\hline ENKTL & $113(32.5)$ & $32(25.2)$ & $81(36.8)$ & & $31(24.6)$ & $82(37.1)$ & \\
\hline AITL & $70(20.2)$ & $27(21.2)$ & 43(19.5) & & $29(23.0)$ & $41(18.6)$ & \\
\hline ALCL,ALK + & $20(5.8)$ & 10(7.9) & $10(4.5)$ & & $8(6.3)$ & $12(5.4)$ & \\
\hline ALCL,ALK- & $21(6.0)$ & $7(5.5)$ & $14(6.3)$ & & $3(2.4)$ & $18(8.1)$ & \\
\hline MEITL & $4(1.2)$ & $3(2.4)$ & $1(0.5)$ & & $1(0.8)$ & $3(1.4)$ & \\
\hline SPTCL & $5(1.4)$ & $2(1.6)$ & $3(1.4)$ & & $1(0.8)$ & $4(1.8)$ & \\
\hline HSTCL & $2(0.6)$ & $1(0.8)$ & $1(0.5)$ & & 2(1.6) & $0(0.0)$ & \\
\hline $\mathrm{MF} / \mathrm{SS}$ & $1(0.3)$ & $0(0.0)$ & $1(0.5)$ & & $0(0.0)$ & $1(0.5)$ & \\
\hline Bone marrow Involvement & & & & $<0.05^{*}$ & & & $<0.05^{*}$ \\
\hline Yes & 119(34.3) & $56(44.1)$ & 63(28.6) & & $75(59.5)$ & 44(19.9) & \\
\hline No & $228(65.7)$ & $71(55.9)$ & 157(71.4) & & $51(40.5)$ & 177(80.1) & \\
\hline Albumin(g/L) & & & & $<0.05^{*}$ & & & $<0.05^{*}$ \\
\hline$<35$ & 112(32.3) & $66(52.0)$ & $46(20.9)$ & & $64(50.8)$ & $48(21.7)$ & \\
\hline$\geq 35$ & $235(67.7)$ & $61(48.0)$ & 174(79.1) & & $62(49.2)$ & $173(78.3)$ & \\
\hline EBV & & & & 0.165 & & & 0.074 \\
\hline Positive & $224(64.6)$ & 88(69.3) & $136(61.8)$ & & $89(70.6)$ & 135(61.1) & \\
\hline Negative & 123(35.4) & 39(30.7) & $84(38.2)$ & & $37(29.4)$ & 86(38.9) & \\
\hline Extra-nodal Involvement & & & & $<0.05^{*}$ & & & $<0.05^{*}$ \\
\hline$>1$ & 163(47.0) & $83(65.4)$ & $80(36.4)$ & & $82(65.1)$ & $81(36.7)$ & \\
\hline 0,1 & 184(53.0) & 44(34.6) & 140(63.6) & & $44(34.9)$ & $140(63.3)$ & \\
\hline Elevated LDH level & & & & $<0.05^{*}$ & & & $<0.05^{*}$ \\
\hline Yes & $222(64.0)$ & 99(78.0) & 123(55.9) & & $100(79.4)$ & $122(55.2)$ & \\
\hline No & $125(36.0)$ & $28(22.0)$ & $97(44.1)$ & & $26(20.6)$ & $99(44.8)$ & \\
\hline Elevated $\beta_{2}-M G$ level & & & & $<0.05^{*}$ & & & $<0.05^{*}$ \\
\hline Yes & $222(64.0)$ & 100(78.7) & $122(55.5)$ & & $97(77.0)$ & $125(56.6)$ & \\
\hline No & $125(36.0)$ & $27(21.3)$ & $98(44.5)$ & & $29(23.0)$ & $96(43.4)$ & \\
\hline $\mathrm{LY}\left(\times 10^{9} / \mathrm{L}\right)$ & $1.06(0.1-7.24)$ & $0.7(0.1-2.5)$ & $1.3(0.1-7.24)$ & $<0.05^{*}$ & $0.9(0.1-6.0)$ & $1.2(0.1-7.24)$ & 0.182 \\
\hline $\mathrm{MONO}\left(\times 10^{9} / \mathrm{L}\right)$ & $0.49(0.04-1.83)$ & $0.64(0.08-1.83)$ & $0.45(0.04-1.34)$ & $<0.05^{*}$ & $0.67(0.04-1.83)$ & $0.42(0.04-1.19)$ & $<0.05^{*}$ \\
\hline
\end{tabular}


Table 1 (continued)

\begin{tabular}{|c|c|c|c|c|c|c|c|}
\hline Characteristic & $\begin{array}{l}\text { Total } \\
(n=347)\end{array}$ & $\begin{array}{l}\mathrm{LMR} \leq 1.68 \\
(\mathrm{n}=127)\end{array}$ & $\begin{array}{l}L M R>1.68 \\
(n=220)\end{array}$ & $p$ value & $\begin{array}{l}P M R \leq 300 \\
(n=126)\end{array}$ & $\begin{array}{l}\mathrm{PMR}>300 \\
(\mathrm{n}=221)\end{array}$ & $p$ value \\
\hline $\operatorname{PLT}\left(\times 10^{9} / \mathrm{L}\right)$ & $178(2-637)$ & $147(14-557)$ & $195.5(2-637)$ & $<0.05^{*}$ & $110(2-537)$ & 213(44-637) & $<0.05^{*}$ \\
\hline Attainment of $C R$ & & & & $<0.05^{*}$ & & & $<0.05^{*}$ \\
\hline Yes & 117(33.7) & $18(14.2)$ & $99(45.0)$ & & 18(14.3) & $99(44.8)$ & \\
\hline No & $230(66.3)$ & 109(85.8) & $121(55.0)$ & & 108(85.7) & $122(55.2)$ & \\
\hline
\end{tabular}

IPI International Prognostic Index, ECOG Eastern Cooperative Oncology Group, PTCL Peripheral T-cell lymphoma, PTCL-NOS PTCL-not otherwise speciffied, ENKTL extra-nodal NK/T-cell lymphoma, nasal type, AITL angioimmunoblastic T-cell lymphoma, ALCL,ALK + anaplastic lymphoma kinase positive, ALCL,ALK - anaplastic lymphoma kinase negative, MEITL monomorphic epitheliotropic intestinal T-cell lymphoma, SPTCL subcutaneous panniculitis-like T-cell lymphoma, HSTCL hepatosplenic T-cell lymphoma, MF/SS mycosisfungoides/Sezary's syndrome, EBV Epstein-barr virus, $L D H$ lactic dehydrogenase, $\beta 2-M G$ beta- 2 micro-globulin, $L Y$ lymphocyte, MONO monocyte, PLT platelet, CR complete response

*Significantly different

Categorical variables are expressed in frequency and percentage ( $n, \%)$; Continuous variables are expressed in median with range of minimum to maximum

\section{Statistical analysis}

Post hoc power analyses were conducted with GPOWER (Faul, Erdfelder, Lang, \& Buchner, 2007) in order to estimate the probability of occurrence of effects in the sample. Through the normal distribution test, the continuous variables included in this study all conform to the normal distribution. The continuous variables such as lymphocyte count, monocyte count and platelet count were shown as median with range and were compared by Mann-Whitney U-test. Other continuous variables were grouped according to the usual clinical threshold and were presented as frequencies and percentages (n, \%) in company with categorical variables. All hierarchical and categorical variables were compared by Pearson's chisquare test. Among them, histological subtypes were performed bonferroni-post-hoc-correction. Kaplan-Meier curve was used to analyze OS and log-rank test was used for comparison. Univariate and multivariate logistic regression models were used to evaluate the correlation between clinical variables and complete remission (CR). Cox proportional hazard regression model was used to analyze univariate and multivariate of OS. Statistical analysis was performed by SPSS 23.0 software package. In all comparisons, the results were considered to be statistically significant when the p value was $<0.05$, and $95 \%$ confidence interval (CI) was given.

\section{Results}

\section{Patients characteristics}

According to the admission conditions, we enrolled 347 patients with newly diagnosed PTCL for analysis and used to establish a prognostic model (Fig. 1). The clinical characteristics and laboratory data were listed in Table 1. The four most common subtypes of PTCLNOS, ENKTL, AITL and ALCL accounted for $32.0 \%$, $32.5 \%, 20.2 \%$ and $11.8 \%$, respectively. Other rare subtypes including MEITL, SPTCL, HSTCL and MF/SS accounted for 3.5\% totally. However, the different subtypes of PTCL did not show statistical significance in the stratification of LMR in our study, either by Pearson's chi square test $(\mathrm{P}=0.330)$ or performing bonferroni-post-hoc-correction $(\mathrm{P}=0.570)$. Although the difference of case typing in PMR was statistically significant through Pearson's chi square test $(\mathrm{P}=0.018)$, the difference was not statistically significant in bonferroni-post-hoc-correction $(\mathrm{P}=0.139)$. The median age at diagnosis was 55 years (rang: $15-84$ years), and among them, $36 \%$ of the elderly patients were over 60 years old. The ratio of male to female was close to $2: 1$. About $81.3 \%$ of patients were in stage III-IV and $58.5 \%$ of them had B symptoms. At the first diagnosis, 32.3\% of patients had albumin below $35 \mathrm{~g} / \mathrm{L}$, and $64.6 \%$ of them were infected with EpsteinBarr virus (EBV). In addition, 163 patients had more than one extra-nodal site involved. The serum lactic dehydrogenase (LDH) and beta-2 micro-globulin ( $\beta 2-\mathrm{MG}$ ) levels were increased in $64 \%$ of the patients, respectively.

All patients received at least two cycles of chemotherapy. Except for all ENKTL patients received the protocol containing Pegaspargase. The rest of patients included in this study were treated with CHOP (cyclophosphamide-doxorubicin-vincristine-prednisone) or CHOPlike chemotherapy. Furthermore, 36 patients proceeded to hemopoietic stem cell transplantation, in which 24 of them accepted autologous stem cell transplantation.

\section{Threshold setting and the relationship between LMR/PMR and clinical parameters and complete remission (CR)} The ROC curve was generated to select the appropriate cutoff values for LMR and PMR based on the survival analysis (Fig. 2). For LMR, the area under curve (AUC) was 0.734 (95\% CI: 0.682-0.786), with a generated maximum joint sensitivity and specificity at the value of 1.68 . In addition, for PMR the AUC was calculated to be 0.718 (95\% CI: 0.664-0.772), with a generated maximum joint 


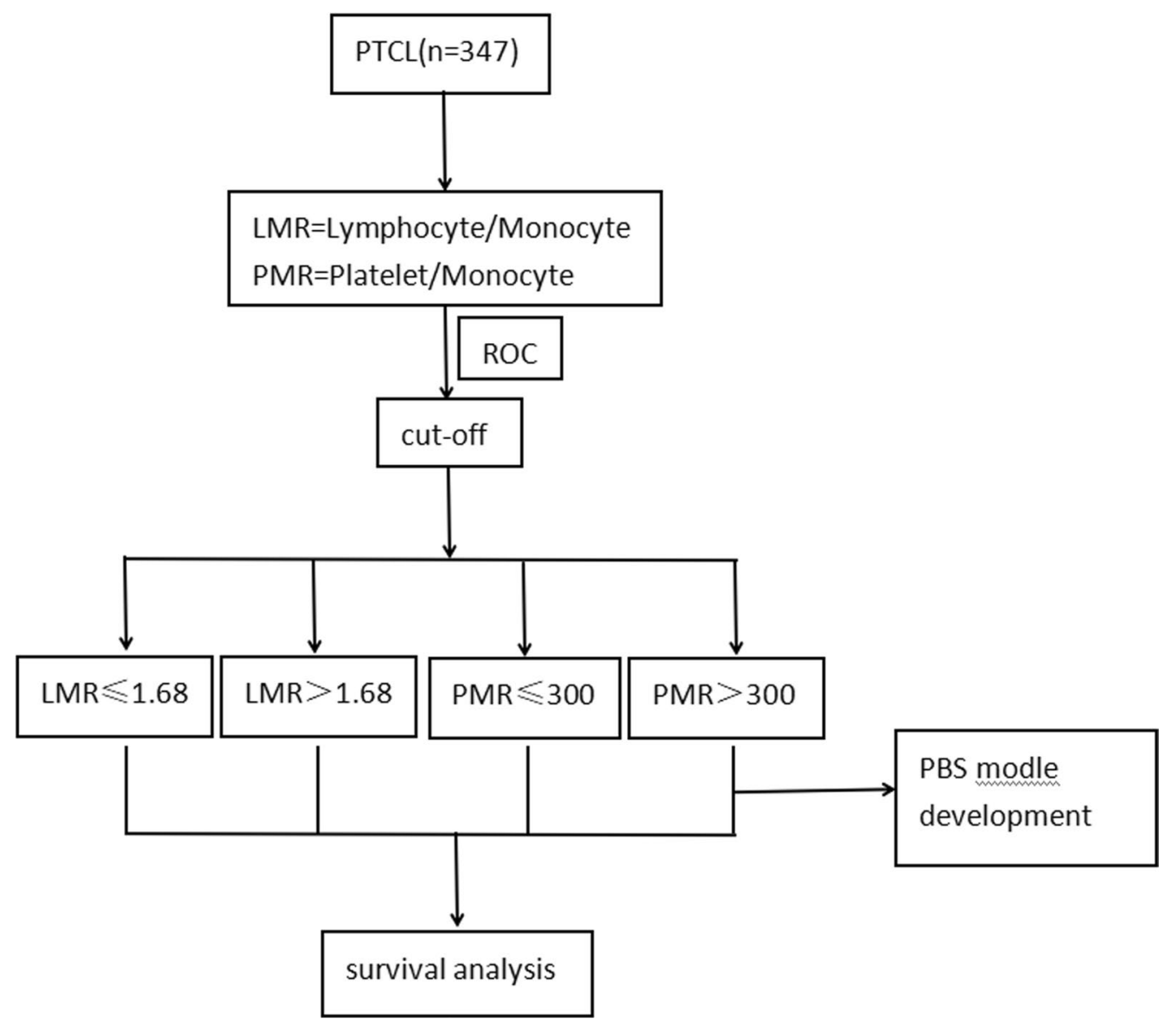

Fig. 1 Flow chart of patients included in the analysis

sensitivity and specificity at the value of 300 . Table 1 compared the clinical characteristics of patients with LMR and PMR at different levels. The high group and low group were defined as being greater than the cutoff value and less or equal to than the cutoff value, respectively. Post hoc analysis demonstrated sufficient power to distinguish the significant differences (power $=0.996$ ). Patients with $\mathrm{LMR} \leq 1.68$ or PMR $\leq 300$, only $14.2 \%$ and $14.3 \%$ of them achieved complete response (CR) after treatment. Therefore, it is not difficult to speculate that patients with $\mathrm{LMR} \leq 1.68$ or $\mathrm{PMR} \leq 300$ may have poor therapeutic effect.

In univariate logistic regression analysis, lower CR rate was related to first diagnosis older than 60 years, IPI $\geq 3$, ECOG $\geq 3$, stage III-IV, B symptoms, bone marrow involvement, Albumin $<35 \mathrm{~g} / \mathrm{L}$, EBV infection, Extra-nodal $>1$, lymphocyte $(\mathrm{LY})\left(\times 10^{9} / \mathrm{L}\right)<0.8$, monocyte $(\mathrm{MONO})\left(\times 10^{9} / \mathrm{L}\right)>1$, platelet $(\mathrm{PLT})\left(\times 10^{9} / \mathrm{L}\right)<83$, elevated LDH and elevated $\beta 2$-MG, LMR $\leq 1.68$ and $P M R \leq 300$ (Table 2). Nevertheless, in the multivariate logistic regression analysis, only first diagnosis older than 60 years $(\mathrm{OR}=4.031,95 \%$ CI 2.021-8.041, $\mathrm{p}<0.001)$, $\mathrm{ECOG} \geq 3(\mathrm{OR}=3.610,95 \%$ CI $1.572-8.290, \mathrm{p}=0.002)$, stage III-IV $(\mathrm{OR}=2.737,95 \% \mathrm{CI} 1.255-5.969, \mathrm{p}=0.011)$, bone marrow involvement $(\mathrm{OR}=2.581,95 \%$ CI $1.173-$ 5.683, $\mathrm{p}=0.018)$ and $\mathrm{EBV}$ infection $(\mathrm{OR}=2.090,95 \%$ CI $1.170-3.734, p=0.013$ ) were statistically significant (Table 2).

\section{The association of LMR/PMR with OS}

In our study, we analyzed the survival of low and high groups of LMR and PMR patients, and found that there were significant differences in OS between all the two groups $(\mathrm{P}<0.001)$ (Fig. 3$)$. The median survival time in the groups with $\mathrm{LMR} \leq 1.68$ and $\mathrm{LMR}>1.68$ were 5 months and 28.5 months, and in the groups with $\mathrm{PMR} \leq 300$ and $\mathrm{PMR}>300$ were 6 months and 28 months, respectively. The univariate analysis of Cox model showed that first diagnosis older than 60 years, IPI $\geq 3$, ECOG $\geq 3$, stage III-IV, B symptoms, bone marrow involvement, decreased albumin, EBV infection, Extra-nodal $>1, \quad \operatorname{LY}\left(\times 10^{9} / \mathrm{L}\right)<0.8, \quad \operatorname{MONO}\left(\times 10^{9} / \mathrm{L}\right)>1$, 


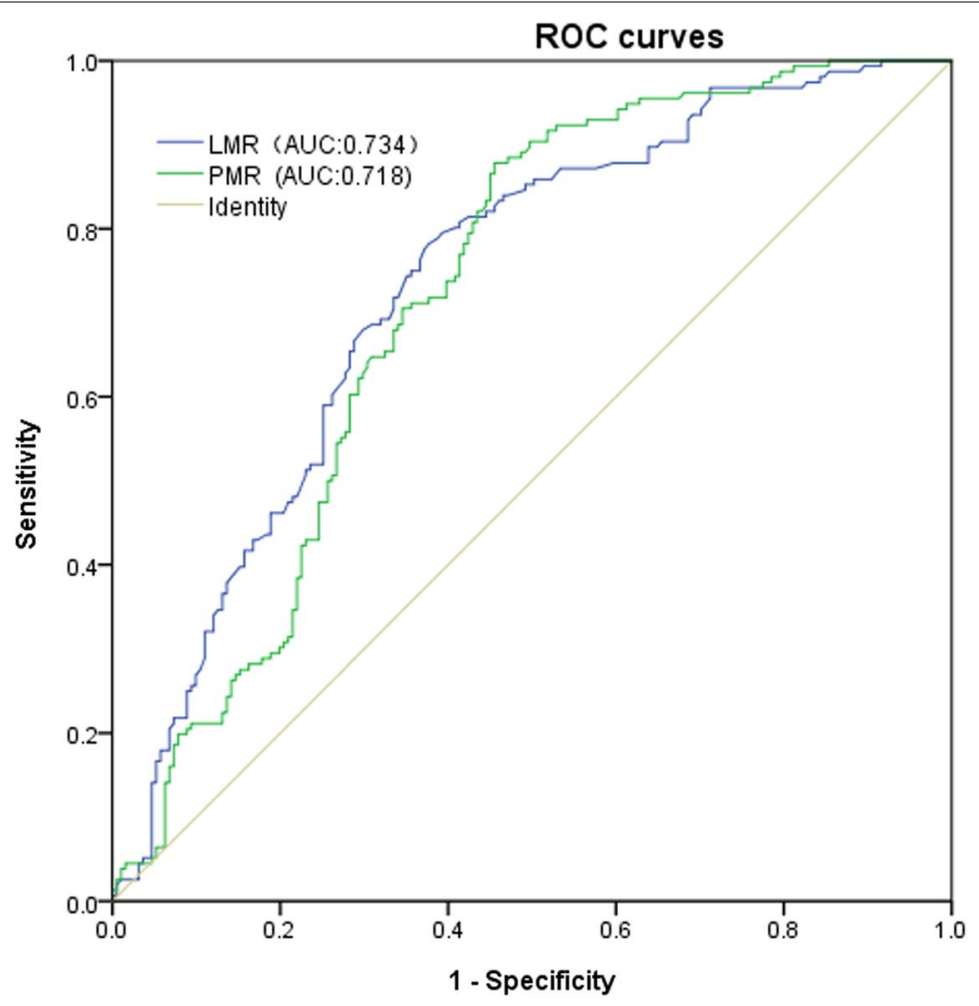

Receiver operating characteristic (ROC) curves of LMR and PMR of patients with PTCL.

\begin{tabular}{cccc}
\hline & AUC & Pvalue & $95 \% \mathrm{Cl}$ \\
\hline LMR & 0.734 & $<0.05$ & $0.682-0.786$ \\
PMR & 0.718 & $<0.05$ & $0.664-0.772$ \\
\hline
\end{tabular}

Fig. 2 Receiver operating characteristic (ROC) curves of $L M R$ and PMR of patients with PTCL

$\operatorname{PLT}\left(\times 10^{9} / \mathrm{L}\right)<83$, elevated LDH, elevated $\beta 2$-MG, $\mathrm{LMR} \leq 1.68$ and $\mathrm{PMR} \leq 300$ were prognostic indicators of OS (Table 3). Then, multivariate analysis was showed only $\quad \mathrm{ECOG} \geq 3 \quad(\mathrm{HR}=2.351,95 \%$ CI $1.647-3.356$, $\mathrm{p}<0.001)$, stage III-IV $(\mathrm{HR}=3.276,95 \%$ CI $1.512-7.099$, $\mathrm{p}=0.003)$, Extra-nodal $>1 \quad(\mathrm{HR}=1.659,95 \%$ CI $1.125-$ $2.445, \mathrm{p}=0.039), \mathrm{LMR} \leq 1.68(\mathrm{HR}=1.751,95 \% \mathrm{CI} 1.158$ 2.647, $\mathrm{p}=0.006)$, and $\mathrm{PMR} \leq 300(\mathrm{HR}=1.762,95 \% \mathrm{CI}$ 1.201-2.586, $\mathrm{p}=0.002)$ were independent prognostic factors for low OS. Moreover, we found that in the low LMR or PMR groups, the proportion of patients with IPI at 3-5 points is higher. Whether in the low-risk group $(I P I=0-2)$ or the high-risk group of IPI (IPI $=3-5)$, the OS of PTCL patients with low LMR group or low PMR group were significantly lower than those of patients in the high LMR group or high PMR group (Fig. 4).

Considering the heterogeneity of PTCL, we analyzed five common pathological subtypes respectively.
Through univariate analysis, it was found that the reduction of LMR and PMR in patients with other common subtypes at the initial diagnosis were significantly correlated with OS except ALCL, ALK+ (Tables 4 and 5). This may be related to the relatively small number of this subtype in our study. However, rare types, such as intestinal $\mathrm{T}$ cell lymphoma (intestinal lymphoma, commonly seen in B cell lymphoma [17]), incidence rate is low, and the number of cases is very small, so rare types are not analyzed separately.

\section{Establishment of PBS model and its correlation with OS}

$\mathrm{LMR} \leq 1.68$ or $\mathrm{PMR} \leq 300$ were counted as 1 point and LMR $>1.68$ or PMR $>300$ were counted as 0 point by detecting the peripheral blood cells count at the initial diagnosis. Patients were divided into three groups: PBS 0 group, PBS 1 group and PBS 2 group. 0 was low-risk group, 1 was intermediate risk group, and 2 was high risk group. The OS of these three groups were statistically 
Table 2 Univariate and multivariate logistic regression models of complete response (CR) in PTCL patients

\begin{tabular}{|c|c|c|c|c|c|c|}
\hline \multirow[t]{2}{*}{ Covariate } & \multicolumn{3}{|c|}{ Univariate analysis } & \multicolumn{3}{|c|}{ Multivariate analysis } \\
\hline & OR & $95 \% \mathrm{Cl}$ & p-value & OR & $95 \% \mathrm{Cl}$ & p-value \\
\hline Sex, Male & 1.590 & $1.001-2.527$ & 0.050 & & & \\
\hline Age, $\geq 60$ years & 3.257 & $1.927-5.505$ & $<0.05^{*}$ & 4.031 & $2.021-8.041$ & $<0.05^{*}$ \\
\hline $\mid \mathrm{PI}, 3-5$ & 5.818 & $3.561-9.506$ & $<0.05^{*}$ & & & \\
\hline $\mathrm{ECOG}, 3-5$ & 7.666 & $3.810-15.423$ & $<0.05^{*}$ & 3.610 & $1.572-8.290$ & $<0.05^{*}$ \\
\hline Stage,III-IV & 7.195 & $3.955-13.088$ & $<0.05^{*}$ & 2.737 & $1.255-5.969$ & $<0.05^{*}$ \\
\hline B symptoms & 2.389 & $1.516-3.766$ & $<0.05^{*}$ & & & \\
\hline Bone marrow & 5.613 & $3.077-10.237$ & $<0.05^{*}$ & 2.581 & $1.173-5.683$ & $<0.05^{*}$ \\
\hline Involvement Albumin, $<35 \mathrm{~g} / \mathrm{L}$ & 2.993 & $1.742-5.141$ & $<0.05^{*}$ & & & \\
\hline EBV,Positive & 2.233 & $1.409-3.541$ & 0.05 & 2.090 & $1.170-3.734$ & $<0.05^{*}$ \\
\hline Extra-nodal, $>1$ & 3.118 & $1.936-5.021$ & $<0.05^{*}$ & & & \\
\hline $\operatorname{LY}\left(\times 10^{9} / \mathrm{L}\right)<0.8$ & 3.565 & $2.042-6.224$ & $<0.05^{*}$ & & & \\
\hline $\operatorname{MONO}\left(\times 10^{9} / \mathrm{L}\right)>1$ & 2.610 & $0.969-7.028$ & 0.058 & & & \\
\hline $\operatorname{PLT}\left(\times 10^{9} / \mathrm{L}\right)<83$ & 7.847 & $2.759-22.318$ & $<0.05^{*}$ & & & \\
\hline Elevated LDH & 2.263 & $1.429-3.585$ & $<0.05^{*}$ & & & \\
\hline Elevated $\beta 2-M G$ & 2.672 & $1.683-4.243$ & $<0.05^{*}$ & & & \\
\hline$L M R \leq 1.68$ & 4.955 & $2.816-8.717$ & $<0.05^{*}$ & 1.996 & $0.906-4.397$ & 0.086 \\
\hline$P M R \leq 300$ & 4.869 & $2.767-8.567$ & $<0.05^{*}$ & 1.851 & $0.873-3.924$ & 0.108 \\
\hline
\end{tabular}

$O R$ odds ratio, $\mathrm{Cl}$ confidence interval

${ }^{*}$ Significantly different

analyzed by Kaplan-Meier curve and log-rank test. It was found that the OS of low-risk, intermediate risk and high risk patients were significantly different. The median OS of the three groups were 32.5 months, 13 months and 5 months respectively $(\mathrm{P}<0.001)$ (Fig. $5,(\mathrm{~A})$ ). Not only that, in the PBS high risk group, $77.4 \%$ of the patients survived for less than 1 year, and only $13.1 \%$ survived for more than 3 years. In the low-risk group with PBS 0 score, $86 \%$ of the patients survived more than 1 year, and $43.4 \%$ of the patients survived for more than 3 years, nearly half of them.

\section{External validation}

In order to verify the PBS model, we collected 44 patients who met the inclusion criteria in Huzhou Hospital of Zhejiang University from November 2013 to March 2021. The final follow-up time was August 2021. The median age of onset was 65 years (range: $32-86$ ), including 24 males and 20 females. The median follow-up was 11 months (range: $1-93$ ). During this period, $59.1 \%$ of patients died due to disease progression or other causes. After substitution into the PBS model, there were 17 cases in the low-risk (38.6\%), 12 cases in the intermediate-risk (27.3\%) and 15 cases in the high-risk (34.1\%). The 1-year OS of the three groups were $88.2 \%, 41.7 \%$ and $6.7 \%$, respectively. The 3 -year OS were $64.7 \%, 16.7 \%$ and 0 , respectively. Although there were differences in the shape of Kaplan-Meier curves between the validation sample and the training sample, there were significant differences in OS among the three groups (Fig. 5). The difference of curve shape may be related to the small number of validation samples and the discontinuity of data.

\section{Discussion}

At present, there is no standardized treatment for PTCL in the world. Whether in first-line treatment, second-line treatment or salvage treatment, the prognosis of PTCL is very poor. There is an urgent need to use accurate predictive models to classify patients at risk. Among all the previously reported indices, IPI and PIT are the most commonly used. It is worth noting that there is considerable overlap in the parameters used to establish the various models and that the patients need to be evaluated by imaging, examination, bone marrow, etc.. The operations are complex, and the establishments of these scoring models are not entirely based on PTCL, so their accuracy are questionable.

With the development of medical science in recent years, more and more attention had been paid to the study of tumor molecular mechanisms, especially in tumor micro-environment. Therefore, the research on PTCL has opened a new chapter.

Gene-expression profiling analysis showed that the clinical behavior of tumors could be determined by the characteristics of the tumor cells and interacted with 


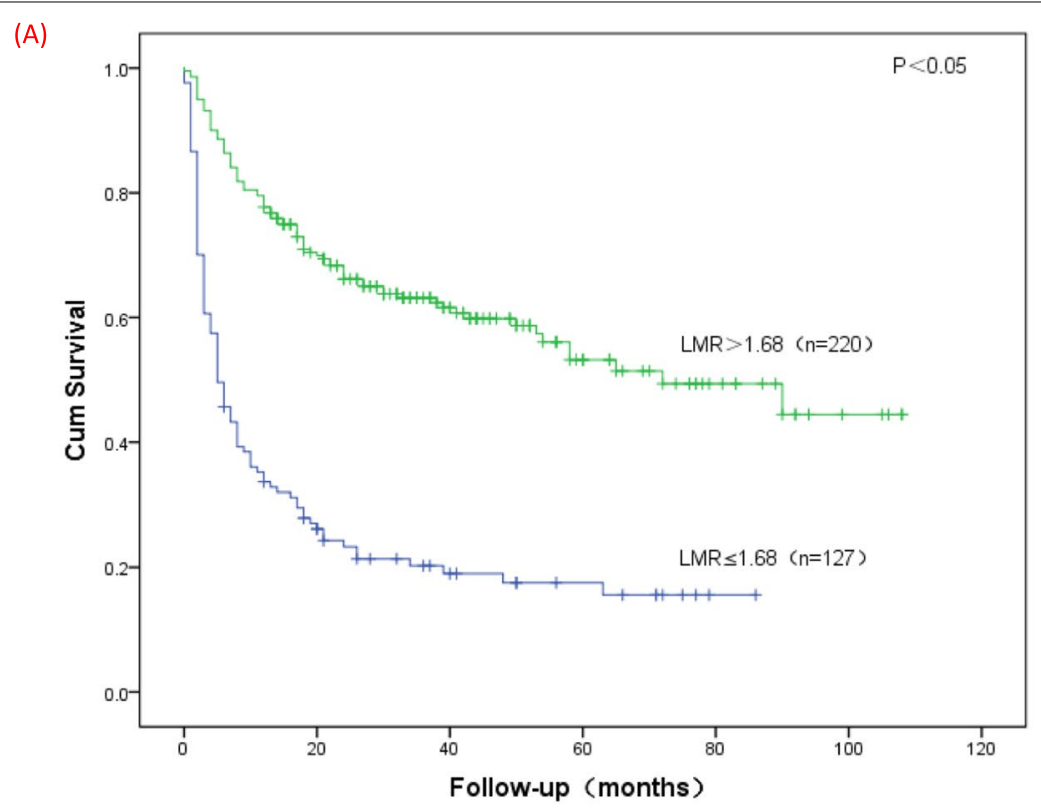

\begin{tabular}{|c|c|c|c|c|c|c|c|}
\hline LMR $>1.68$ & 220 & $135(61.4)$ & $73(33.2)$ & $32(14.5)$ & $15(6.8)$ & $4(1.8)$ & 0 \\
\hline LMR $\leqslant 1.68$ & 127 & $28(22.0)$ & $14(11.0)$ & $9(7.1)$ & $1(0.8)$ & 0 & 0 \\
\hline
\end{tabular}

(B)

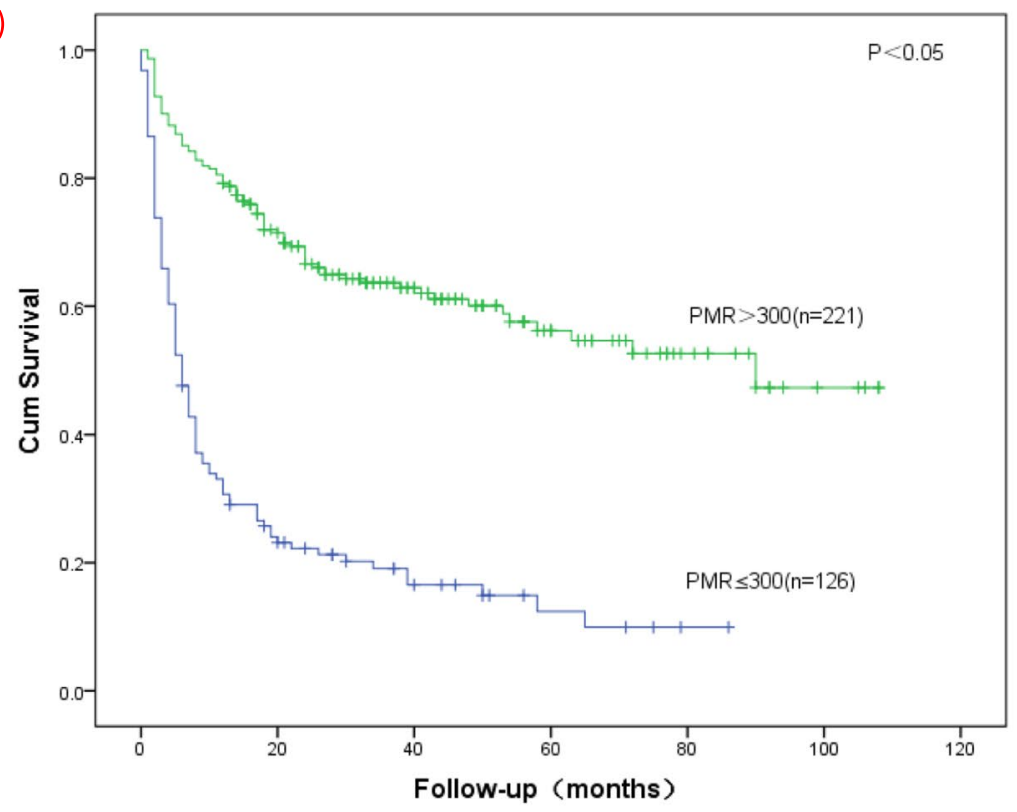

Number at risk by time: $\mathrm{n}(\%)$

\begin{tabular}{llllllll}
\hline $\mathrm{PMR}>300$ & 221 & $137(62.0)$ & $75(33.9)$ & $36(16.3)$ & $15(6.8)$ & $4(1.8)$ & 0 \\
\hline $\mathrm{PMR} \leqslant 300$ & 126 & $26(20.6)$ & $12(9.5)$ & $5(4.0)$ & $1(0.8)$ & 0 & 0 \\
\hline
\end{tabular}

OS for different levels of LMR and PMR. (A) OS for different levels of LMR; (B) OS for different levels of PMR.

Fig. 3 OS for different levels of LMR and PMR. A OS for different levels of LMR; $\mathbf{B}$ OS for different levels of PMR 
Table 3 Univariate and multivariate Cox proportional hazard regression models for overall survival (OS) in PTCL patients

\begin{tabular}{|c|c|c|c|c|c|c|}
\hline \multirow[t]{2}{*}{ Covariate } & \multicolumn{3}{|c|}{ Univariate analysis } & \multicolumn{3}{|c|}{ Multivariate analysis } \\
\hline & HR & $95 \% \mathrm{Cl}$ & $p$-value & $\mathrm{HR}$ & $95 \% \mathrm{Cl}$ & p-value \\
\hline Sex, Male & 1.223 & $0.899-1.662$ & 0.200 & & & \\
\hline Age, $\geq 60$ years & 1.379 & $1.032-1.843$ & $0.030^{*}$ & & & \\
\hline $\mid \mathrm{PI}, 3-5$ & 3.124 & $2.265-4.307$ & $<0.05^{*}$ & & & \\
\hline ECOG, 3-5 & 3.775 & $2.820-5.054$ & $<0.05^{*}$ & 2.351 & $1.647-3.356$ & $<0.05^{*}$ \\
\hline Stage, III-IV & 7.859 & $3.862-15.993$ & $<0.05^{*}$ & 3.276 & $1.512-7.099$ & $<0.05^{*}$ \\
\hline B symptoms & 2.101 & $1.542-2.862$ & $<0.05^{*}$ & & & \\
\hline Bone marrow & 3.062 & $2.297-4.082$ & $<0.05^{*}$ & & & \\
\hline Involvement Albumin, $<35 \mathrm{~g} / \mathrm{L}$ & 2.209 & $1.656-2.946$ & $<0.05^{*}$ & & & \\
\hline EBV, Positive & 1.390 & $1.024-1.887$ & $0.035^{*}$ & & & \\
\hline Extra-nodal, $>1$ & 3.207 & $2.374-4.331$ & $<0.05^{*}$ & 1.659 & $1.125-2.445$ & $0.039^{*}$ \\
\hline $\operatorname{LY}\left(\times 10^{9} / \mathrm{L}\right)<0.8$ & 2.279 & $1.706-3.045$ & $<0.05^{*}$ & & & \\
\hline $\mathrm{MONO}\left(\times 10^{9} / \mathrm{L}\right)>1$ & 2.292 & $1.492-3.523$ & $<0.05^{*}$ & & & \\
\hline $\operatorname{PLT}\left(\times 10^{9} / \mathrm{L}\right)<83$ & 3.459 & $2.471-4.841$ & $<0.05^{*}$ & & & \\
\hline Elevated LDH & 1.613 & $1.182-2.200$ & $<0.05^{*}$ & & & \\
\hline Elevated $\beta 2-M G$ & 2.159 & $1.560-2.986$ & $<0.05^{*}$ & & & \\
\hline$L M R \leq 1.68$ & 3.496 & $2.617-4.669$ & $<0.05^{*}$ & 1.751 & $1.158-2.647$ & $<0.05^{*}$ \\
\hline$P M R \leq 300$ & 3.947 & $2.947-5.287$ & $<0.05^{*}$ & 1.762 & $1.201-2.586$ & $<0.05^{*}$ \\
\hline
\end{tabular}

$H R$ hazard ratio, $\mathrm{Cl}$ confidence interval

${ }^{*}$ Significantly different

non-neoplastic cells [18]. A growing body of research has consistently shown that tumor-associated inflammatory response is a key determinant of prognosis in cancer patients [19]. ALC is an important indicator of host immune status and was also included in the IPS model used to evaluate the prognosis of patients with Hodgkin's lymphoma [20]. Monocytes can produce a variety of cytokines, such as TNF- $\alpha$ - IL-1, IL-10 and IL-6 to promote tumorigenesis, angiogenesis and distant metastasis [21]. In previous retrospective studies, we found an closely association between increased serum Interleukin-10 levels and low survival and early recurrence in patients with PTCL [22]. It also indirectly confirmed that lymphocytes and monocytes were closely related to the prognosis of PTCL.

About 2-9\% of peripheral leukocytes are peripheral blood monocytes (PBMC), but only $40 \%$ of them are used for monocyte circulation, while $60 \%$ of monocytes migrate [23]. However, some immature PBMC can differentiate into specialized, tissue-specific macrophages and Antigen-presenting cells (APC). Their differentiation directly determines their functions. The differentiated monocytes/macrophages (Mphi) plays a specific role in the cell mediated innate immunity against infection, immunoregulation, morphogenetic remodelling and malignancy or tissue repair [24, 25]. Zhu et al. [9] found that LMR was associated with TILs/TAMs (Tumor-associated macrophages) ratio, and that low LMR had worse
OS in patients with esophageal squamous cell carcinoma. It suggests that a systemic inflammatory response may reflect concurrent focal inflammation in the tumor.

Iacono et al. retrospectively analyzed 165 patients with advanced melanoma. The severity and prognosis of the disease were assessed. The decrease of LMR suggests short OS and more distant metastatic sites in malignant melanoma [10]. Wang et al. reported 355 cases of diffuse large B-cell lymphoma (DLBCL). In the low LMR group, PFS and OS were shorter and M2-TAM content was higher. These results suggested that weak antitumor immunity may be an adverse prognostic factor for aggressive lymphoma, identified in high-risk patients [14]. Thus, lymphocyte counts, monocyte counts, and LMR surrogate markers of tumor micro-environment had been reported as prognostic factors for B cell lymphoma [14-16]. Similarly, recent studies had shown that both lymphocyte counts and monocyte counts could predict the clinical outcome of T-cell lymphomas [24-26]. And patients with T-cell lymphomas after autologous peripheral hematopoietic stem cell transplantation had longer OS and PFS with autograft lymphocyte-to-monocyte ratio (A-LMR) greater than or equal to 1 . Compared with patients with A-LMR less than 1, the five years OS rate was $87 \%$ to $26 \%$, and the five years PFS rate was $72 \%$ to $16 \%$, significant difference [26]. Feng et al. [27] Studied 75 newly diagnosed T-lymphoblastic lymphoma (T-LBL) patients and found that patients with $L M R \leq 2.8$ had 
(A)

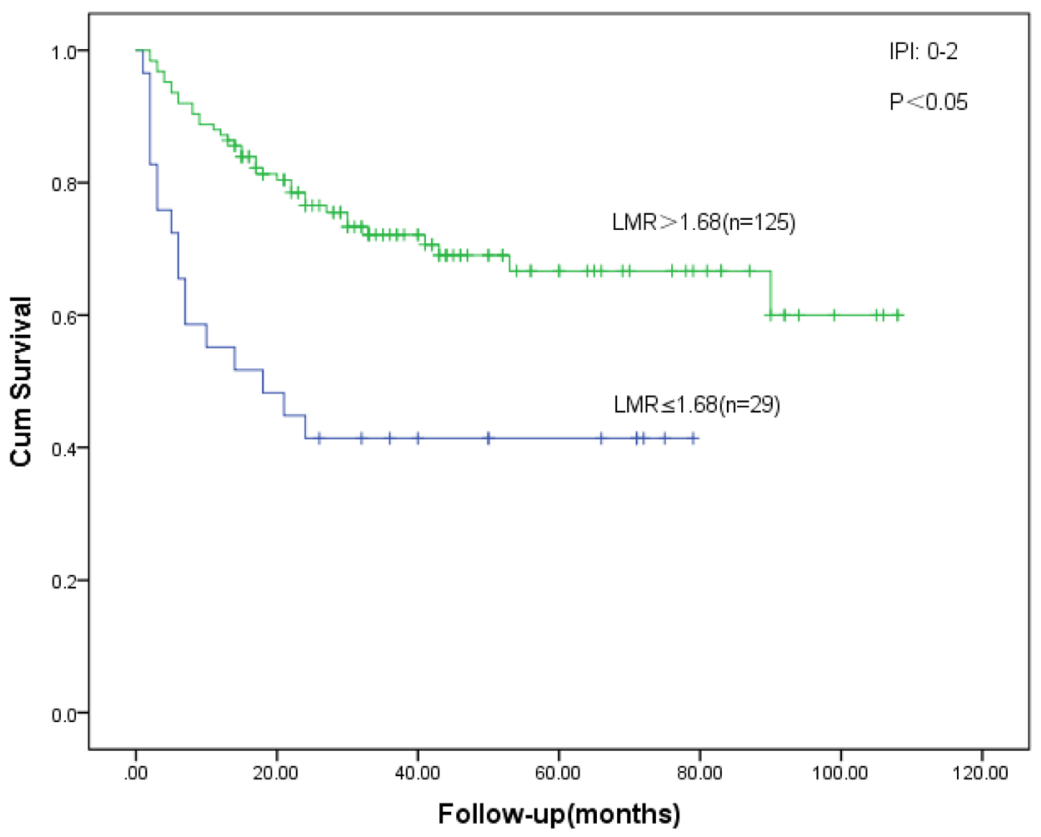

Number at risk by time: $\mathrm{n}(\%)$

\begin{tabular}{cccccccc}
\hline LMR $>1.68$ & 125 & $88(70.4)$ & $49(39.2)$ & $23(18.4)$ & $14(11.2)$ & $4(3.2)$ & 0 \\
\hline$L M R \leqslant 1.68$ & 29 & $14(48.3)$ & $8(27.6)$ & $6(20.7)$ & 0 & 0 & 0
\end{tabular}

(B)

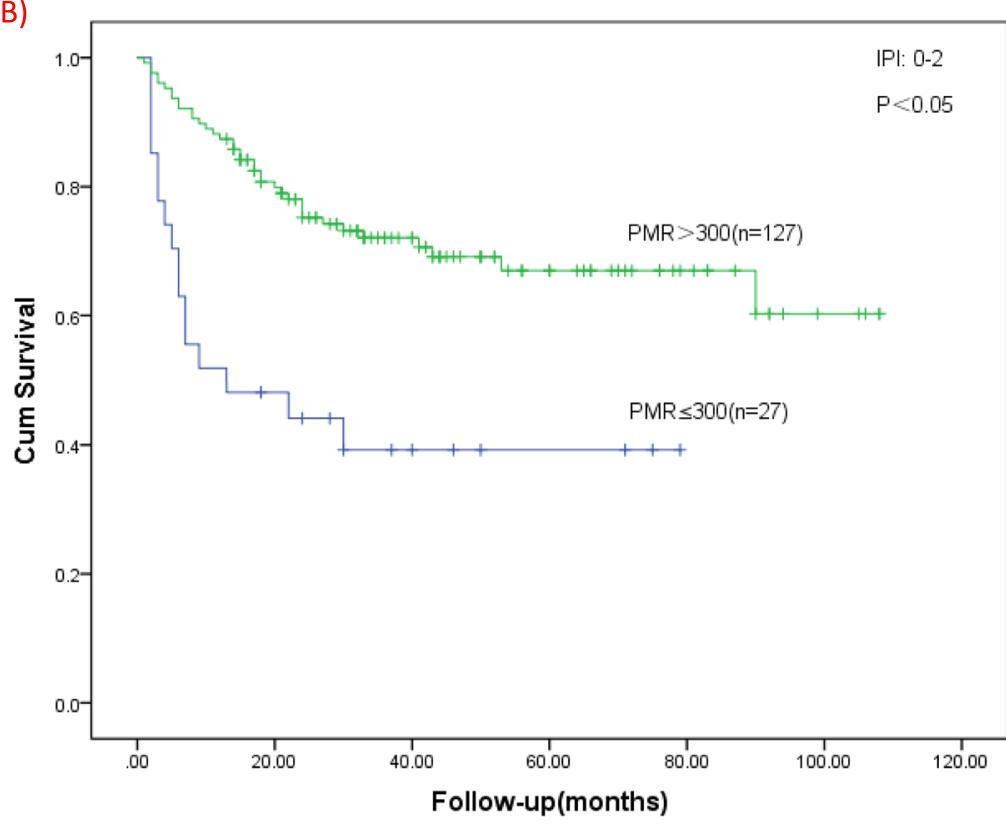

Number at risk by time: $\mathrm{n}(\%)$

\begin{tabular}{lccccccc}
\hline $\mathrm{PMR}>300$ & 127 & $90(70.9)$ & $51(40.2)$ & $26(20.5)$ & $14(11.0)$ & $4(3.1)$ & 0 \\
\hline $\mathrm{PMR} \leqslant 300$ & 27 & $12(44.4)$ & $5(18.5)$ & $3(11.1)$ & 0 & 0 & 0
\end{tabular}

Fig. 4 OS for different IPI risk stratification of PTCL patients. A OS of patients with different LMR levels in group of IPI score 0-2; B OS of patients with different PMR levels in group of IPI score $0-2 ;$ C OS of patients with different LMR levels in group of IPI score 3-5; D OS of patients with different PMR levels in group of IPI score 3-5 


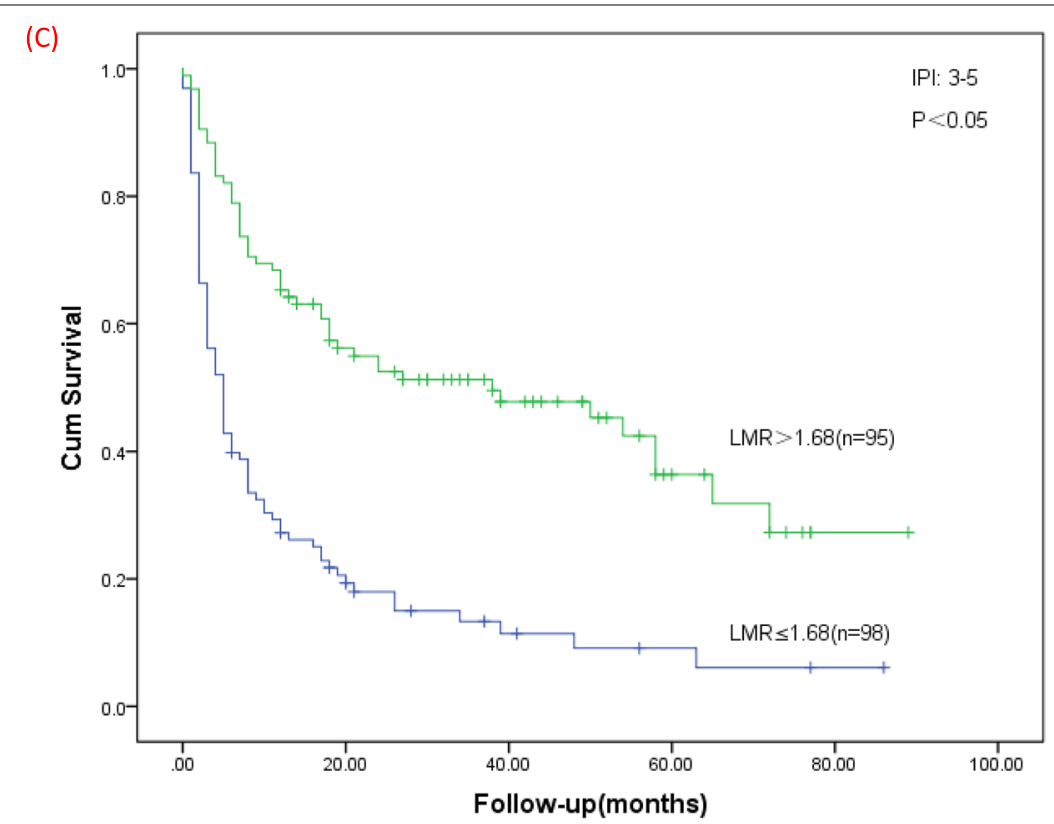

Number at risk by time: $\mathrm{n}(\%)$

\begin{tabular}{lllllll}
\hline $\mathrm{LMR}>1.68$ & 95 & $47(49.5)$ & $25(26.3)$ & $9(9.5)$ & $1(1.1)$ & 0 \\
\hline $\mathrm{LMR} \leqslant 1.68$ & 98 & $14(14.3)$ & $6(6.1)$ & $3(3.1)$ & $1(1.0)$ & 0
\end{tabular}

(D)

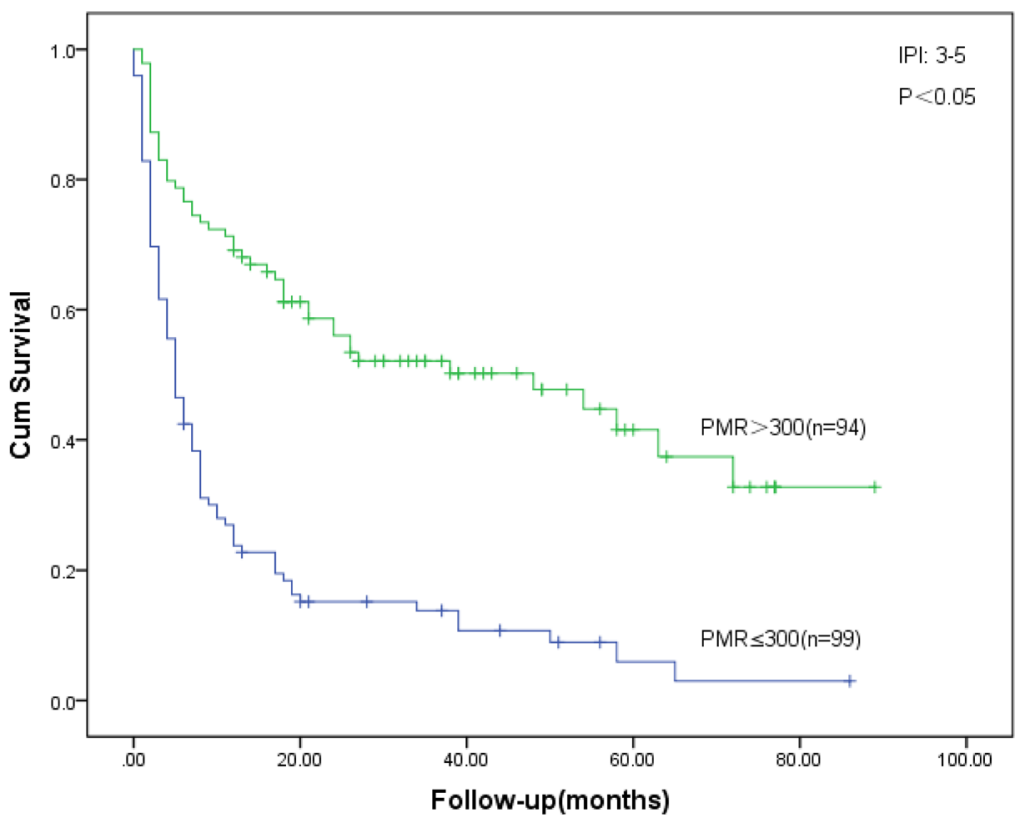

Number at risk by time: $n(\%)$

\begin{tabular}{lcccccc}
\hline $\mathrm{PMR}>300$ & 94 & $47(50.0)$ & $24(25.5)$ & $10(10.6)$ & $1(1.1)$ & 0 \\
\hline $\mathrm{PMR} \leqslant 300$ & 99 & $15(15.2)$ & $7(7.1)$ & $2(2.0)$ & $1(1.0)$ & 0
\end{tabular}

Fig. 4 continued 
Table 4 The significance of LMR in univariate and multivariate analysis of OS in patients with five major subtypes of PTCL

\begin{tabular}{|c|c|c|c|c|c|c|c|}
\hline \multirow{2}{*}{$\begin{array}{l}\text { Histological } \\
\text { Subtype-LMR }\end{array}$} & \multirow[t]{2}{*}{$\mathrm{n}$} & \multicolumn{3}{|c|}{ Univariable analysis } & \multicolumn{3}{|c|}{ Multivariable analysis } \\
\hline & & HR & $95 \% \mathrm{Cl}$ & $p$ value & HR & $95 \% \mathrm{Cl}$ & $\mathrm{p}$ value \\
\hline PTCL,NOS & 111 & 4.525 & $2.738-7.475$ & $<0.05^{*}$ & 2.691 & $1.175-6.162$ & $0.019^{*}$ \\
\hline ENKTL & 113 & 4.820 & $2.854-8.138$ & $<0.05^{*}$ & 1.027 & $0.464-2.276$ & 0.947 \\
\hline AITL & 70 & 1.908 & $1.013-3.591$ & $0.045^{*}$ & 1.785 & $0.844-3.775$ & 0.129 \\
\hline $\mathrm{ALCL}, \mathrm{ALK}+$ & 20 & 5.131 & $0.570-46.172$ & 0.145 & - & - & - \\
\hline ALCL,ALK - & 21 & 7.102 & $1.740-28.982^{*}$ & $<0.05^{*}$ & 1.415 & $0.120-16.636$ & 0.782 \\
\hline
\end{tabular}

$H R$ hazard ratio, $\mathrm{Cl}$ confidence interval

* Significantly different

Table 5 The significance of PMR in univariate and multivariate analysis of OS in patients with five major subtypes of PTCL

\begin{tabular}{|c|c|c|c|c|c|c|c|}
\hline \multirow{2}{*}{$\begin{array}{l}\text { Histological } \\
\text { Subtype-PMR }\end{array}$} & \multirow[t]{2}{*}{$\mathrm{n}$} & \multicolumn{3}{|c|}{ Univariable analysis } & \multicolumn{3}{|c|}{ Multivariable analysis } \\
\hline & & HR & $95 \% \mathrm{Cl}$ & p value & HR & $95 \% \mathrm{Cl}$ & $\mathrm{p}$ value \\
\hline PTCL,NOS & 111 & 4.106 & $2.468-6.830$ & $<0.05^{*}$ & 2.010 & $0.941-4.293$ & 0.071 \\
\hline ENKTL & 113 & 4.732 & $2.777-8.064$ & $<0.05^{*}$ & 2.260 & $1.062-4.812$ & $0.034^{*}$ \\
\hline AITL & 70 & 3.807 & $1.986-7.297$ & $<0.05^{*}$ & 2.962 & $1.313-6.684$ & $<0.05^{*}$ \\
\hline $\mathrm{ALCL}, \mathrm{ALK}+$ & 20 & 8.386 & $0.927-75.846$ & 0.058 & - & - & - \\
\hline ALCL,ALK - & 21 & 8.046 & $1.594-40.602$ & $0.012^{*}$ & 1.622 & $0.090-29.096$ & 0.743 \\
\hline
\end{tabular}

$H R$ hazard ratio, $\mathrm{Cl}$ confidence interval

${ }^{*}$ Significantly different

both inferior progression-free survival (PFS) and inferior overall survival (OS), in which the differences were much more remarkable in the international prognostic index score $0-2$ subgroup. However, the cutoff value of LMR in our study is inconsistent with the result by Feng et al. Feng et al. mainly focused on the T-LBL patients, while our work included the five most common subtypes and four rare subtypes of PTCL. Perhaps, the different inclusion criteria led to the different cutoff values of LMR. For all that, LMR is still an independent prognostic factor for affecting the survival of PTCL patients. Suman Ghosh et al. Present the case of a T-LBL with superior vena cava syndrome, developing tumor lysis syndrome on instituting definitive chemotherapy in a young patient. From the patient's blood cell count, although we cannot know the accurate monocyte values, it is not difficult to speculate that the patient's LMR is greater than 1.68 and the prognosis is relatively good, which is also consistent with the good follow-up clinical outcome of the patient mentioned in the article [28].

The average platelet count in humans is between $150 \times 10^{9}$ and $400 \times 10^{9}$ per liter, but over time, the number of individual platelets remains the same [29]. Platelets mainly participates in the organism haemostasis and the thrombosis. In recent years, there are increasing evidences that platelets and tumor cells have significant cross-communication, suggesting that they play an important role in the progression of malignant tumors, the occurrence of tumor-associated local inflammation, and cancer-associated thrombosis. On the one hand, tumors can affect the RNA profile of platelets, the number of circulating platelets and their activation status. On the other hand, tumor-induced platelets contain a large number of active biomolecules, including plateletspecific and circularly ingested biomolecules that are released upon activation of platelets and are involved in the development of malignant tumors [30].

Platelet activation plays an important role in tumorassociated immune thrombosis and multiple metastasis. Activated platelets were known to secrete a range of inflammatory chemokines that activate inflammatory signaling pathways in white blood cells, including PAF, RANTES, CCL3, CXCL1, CXCL4 (platelet factor 4), and CXCL7 [31, 32]. Serotonin (5-hydroxytryptamine) is another platelet-releasing product that may affect monocyte function. Monocytes exposed to 5-hydroxytryptamine showed increased NF-kB activation, increased cytokine production induced by LPS, and decreased apoptosis, possibly due to changes in BCL-2 or MCL-1 expression [33]. Białas et al. [13] Found that the ratio of monocyte to platelet can be used as a prediction tool for pulmonary embolism in 
(A)

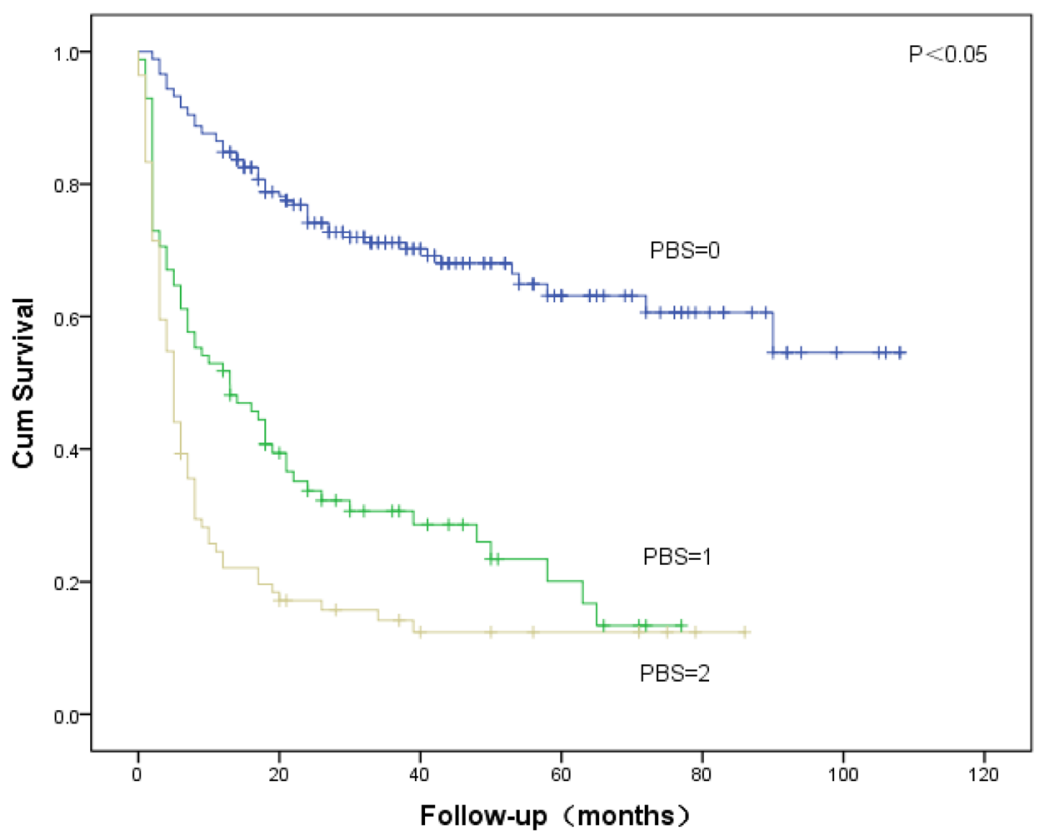

Number at risk by time: $n(\%)$

\begin{tabular}{cccccccc}
\hline PBS=0(Low) & 178 & $122(68.5)$ & $67(37.6)$ & $31(17.4)$ & $15(8.4)$ & $4(2.2)$ & 0 \\
\hline PBS=1(Interm.) & 85 & $29(34.1)$ & $14(16.5)$ & $6(7.1)$ & 0 & 0 & 0 \\
PBS=2(High) & 84 & $12(14.3)$ & $6(7.1)$ & $4(4.8)$ & $1(1.2)$ & 0 & 0
\end{tabular}

(B)

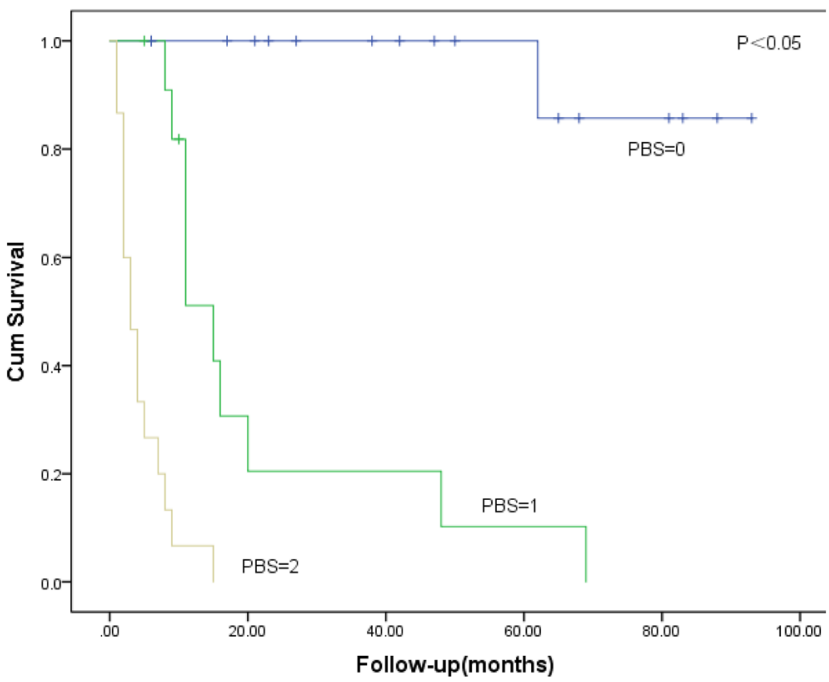

Number at risk by time: $\mathrm{n}(\%)$

\begin{tabular}{ccccccc}
\hline $\mathrm{PBS}=0$ (Low) & 17 & $14(82.4)$ & $10(58.8)$ & $7(41.2)$ & $4(23.5)$ & 0 \\
\hline $\mathrm{PBS}=1$ (Interm.) & 12 & $2(16.7)$ & $2(16.7)$ & $1(8.3)$ & 0 & 0 \\
$\mathrm{PBS}=2$ (High) & 15 & 0 & 0 & 0 & 0 & 0 \\
\hline
\end{tabular}

Fig. 5 Kaplan-Meier curves of overall survival by risk groups identified by the PBS model in the training sample $(n=347)(\mathbf{A})$ and in the validation sample $(n=44)(B)$. Interm., intermediate 
acute deteriorate of chronic obstructive pulmonary disease (AECOPD). In the past few decades, a large number of clinical studies have shown that daily aspirin can reduce the incidence, metastasis and mortality of tumors, especially for colorectal cancer [34]. In addition, platelets are closely associated with the complement system [35]. To date, platelets have been suggested as an adverse predictor of survival in PTCL Mechanistically, thrombocytopenia impairs the immune response, increases the risk of bleeding, and reflects the bone marrow failure, indicting a poor prognosis in patients with PTCL [36]. Recently, Guillem-Llobat and his collaborators demonstrated in an immunodeficiency mouse model that low-dose aspirin reduces the metastasis of lung cancer by avoiding the enhanced pro-aggregation effect caused by platelettumor cell interaction [37]. These clinical studies have fully confirmed that platelets are closely related to the occurrence and development of PTCL.

In recent years, many clinical studies had shown that hematological components of the systemic inflammatory response, including the lymphocyte-to-monocyte ratio (LMR), the platelet-to-moncyte ratio (PMR) and the systemic immune inflammation index (SII) are efficient prognostic indicators in patients with cancers. The decrease of LMR has been confirmed by many clinical studies to be related to the poor prognosis of esophageal cancer, melanoma, Hodgkin's lymphoma, multiple myeloma and DLBCL [9, 10, 38-40]. PMR has also been proved to play an important role in the early warning of pulmonary embolism in patients with AECOPD [13]. But most of the studies did not investigate the reference intervals (RIs) of these parameters in healthy controls. Luo et al. Conducted a retrospective cohort study of 5969 Chinese healthy people aged 18 to 79 by retrieving the data from the health routine examination center database and laboratory information system of four participating centers in Western China. They found that the individual's gender can significantly influence LMR. Surprisingly, they also found that with an increase in age, the LMR tend to decrease. The RIs of LMR was 2.63-9.9 [41]. Another healthy population study from Iran. They included the data of 2212 healthy subjects and the average age was $47.9 \pm 9.29$ years. The mean value of LMR was $11.15 \pm 3.14$ [42]. There are significant differences between the two values above for healthy people, which may be related to the age and population differences of subjects. However, regardless of the reference range, the cut-off value of LMR obtained in our study is significantly lower than the reference ranges. Unfortunately, the RIs of PMR in normal population has not been clarified.

\section{Conclusions}

The present study showed the correlation between readily available peripheral blood biomarkers and survival in patients with PTCL. LMR $\leq 1.68$ and PMR $\leq 300$ were significantly associated with lower CR rate and poorer OS and were regarded as independent prognostic factors by univariable and multivariable analysis. The PBS model based on LMR and PMR can well distinguish high-risk patients, and we have also been well verified after substituting the clinical data of another center. Compared with the current IPI and PIT models, our PBS model is more simple, inexpensive and widely available, which could help improve the risk stratification and guide clinicians to make better treatment strategies.

Our study still has some limitations. Firstly, the retrospective study may be biased in the selection of patients. Secondly, the dynamic changes of patients during treatment did not taken into account during analysis. Third, our sample size is relatively small and lack of cytogenetic data. Another issue is the cut-off value of $L M R / P M R$ used in clinical practice. In the past and in our study, the ROC curve based on survival was used to determine the optimal cut-off value, indicating that there was inconsistency between the centers. Therefore, further exploration and prospective trials with larger samples are needed in the future and the PBS model we established also needs further verification.

\section{Abbreviations}

PTCL: Peripheral T-cell lymphoma; NHL: Non-Hodgkin's lymphoma; CR: Complete response; OS: Overall survival; ECOG: Eastern cooperative oncology group; LMR: Lymphocyte-monocyte ratio; PMR: Platelet-monocyte ratio; PBS: Peripheral blood score; CBC: Blood cell count; PTCL-NOS: Peripheral T-cell lymphoma, not otherwise specified; ENKTL: Extra-nodal natural killer (NK)/T cell lymphoma, nasal type; AITL: Angioimmunoblastic T-cell lymphoma; ALK + ALCL: Anaplastic lymphoma kinase positive anaplastic large cell lymphoma; ALK - ALCL: Anaplastic lymphoma kinase negative anaplastic large cell lymphoma; MEITL: Monomorphic epitheliotropic intestinal T-cell lymphoma; SPTCL: Subcutaneous panniculitis like T-cell lymphoma; MF/SS: Mycosisfungoides/Sezary's syndrome; HSTCL: Hepatosplenic T-cell lymphoma; IPI: International Prognostic Index; LDH: Lactic dehydrogenase; TAMs: Tumor-associated macrophages; ROC: Receiver operating characteristic; Cl: Confidence interval; EBV: Epstein-Barr virus; $\beta 2-M G$ : Beta-2 microglobulin; LY: Lymphocyte; MONO: Monocyte; PLT: Platelet; PBMC: Peripheral blood monocytes; APC: Antigen-presenting cells; Mphi: Monocytes/macrophages; DLBCL: Diffuse large B-cell lymphoma; PFS: Progression free survival; A-LMR: Autograft lymphocyte-to-monocyte ratio; HSC: Hematopoietic stem cells; TF: Tissue factor.

\section{Acknowledgements}

The authors thank the practitioners who helped to collect and sort out the patient' information and follow-up and thank the patients for allowing us to analyze their data.

\section{Authors' contributions}

All authors read and approved the final manuscript. WX designed the study. $Y Z, Y S, X Z, L S, Q F, H S, M Z, X H, J H, L L, D Z, L Z, J Z, X Y$ and JJ collected the patients' material. $Y Z$ and $Y S$ analyzed data and wrote the paper. 


\section{Funding}

Not applicable.

\section{Availability of data and materials}

All data included in our manuscript were real clinical data. However, because this was a retrospective clinical study, the original blood samples have been unable to obtain, so the data used were all obtained from the previous patients' in-hospital tests, without repeated tests.

\section{Declarations}

\section{Ethics approval and consent to participate}

The studies involving human participants were reviewed and approved by Clinical Research ethics committee of the First Affiliated Hospital of Medical College of Zhejiang University. The patients signed informed consents to participate in this study.

\section{Consent for publication}

All authors agreed to publish this manuscript. There is no copyright conflict.

\section{Competing interests}

The authors declare that they have no competing interests.

\section{Author details}

'Department of Hematology, College of Medicine, Affiliated Huzhou Hospital, Zhejiang University, No. 1558 North Third Ring Road, Huzhou 313000, Zhejiang, China. ${ }^{2}$ Department of Hematology, College of Medicine, the First Affiliated Hospital, Zhejiang University, No. 79 Qingchun Road, Hangzhou 310003, Zhejiang, China. ${ }^{3}$ Key Laboratory of Hematologic Malignancies, Diagnosis and Treatment, Hangzhou 310003, Zhejiang, China.

Received: 3 August 2021 Accepted: 18 October 2021

Published online: 29 October 2021

\section{References}

1. A clinical evaluation of the Inernational Lymphoma Study Group classification of non-Hodgkin's lymphoma. The non-Hodgkin's lymphoma classification project. Blood. 1997;89(11):3909-18.

2. Shi Y. Current status and progress of lymphoma management in China. Int J Hematol. 2018;107(4):405-12.

3. Weisenburger DD, Savage KJ, Harris NL, Gascoyne RD, Jaffe ES, MacLennan KA, Rudiger T, Pileri S, Nakamura S, Nathwani B, Campo E, Berger F, Coiffier B, Kim WS, Holte H, Federico M, Au WY, Tobinai K, Armitage JO, Vose JM. Peripheral T-cell lymphoma, not otherwise specified: a report of 340 cases from the International Peripheral T-cell Lymphoma Project. Blood. 2011;117:3402-8.

4. Bellei M, Foss FM, Shustov AR, Horwitz SM, Marcheselli L, Kim WS, Cabrera ME, Dlouhy I, Nagler A, Advani RH, Pesce EA, Ko YH, Martinez V, Montoto S, Chiattone C, Moskowitz A, Spina M, Biasoli I, Manni M, Federico M. The outcome of peripheral T-cell lymphoma patients failing first line therapy: a report from the prospective, international T-Cell project. Haematologica. 2018;103:1191-7.

5. Mak V, Hamm J, Chhanabhai M, et al. Survival of patients with peripheral T-cell lymphoma after first relapse or progression: spectrum of disease and rare long-term survivors. JCO. 2013;31(16):1970-6.

6. Iqbal J, Wright $G$, Wang C. Gene expression signatures delineate biological and prognostic subgroups in peripheral T-cell lymphoma. Blood. 2014;123:2915-23.

7. Gallamini A, Stelitano C, Calvi R, Bellei M, Mattei D, Vitolo U, Morabito F, Martelli M, Brusamolino E, lannitto E, Zaja F, Cortelazzo S, Rigacci L, Devizzi L, Todeschini G, Santini G, Brugiatelli M, Federico M. Peripheral T-cell lymphoma unspecified (PTCL-U): a new prognostic model from a retrospective multicentric clinical study. Blood. 2004;103:2474-9.

8. Germano G, Allavena P. Mantovani A. Cytokines as a key component of cancer-related inflammation. Cytokine. 2008;43(3):374-9.

9. Zhu Y, Li M, Bo C, Liu X, Zhang J, Li Z, Zhao F, Kong Li, Jinming Yu. Prognostic significance of the lymphocyte-to-monocyte ratio and the tumor-infiltrating lymphocyte to tumor-associated macrophage ratio in patients with stage T3NOMO esophageal squamous cell carcinoma. Cancer Immunol Immunother. 2017;66(3):343-54.

10. Iacono D, Basile D, Gerratana L, Vitale MG, Pelizzari G, Cinausero M, Poletto E, Puglisi F, Fasola G, Minisini AM. Prognostic role of disease extent and lymphocyte-monocyte ratio in advanced melanoma. Ann Oncol. 2017. https://doi.org/10.1093/annonc/mdx428.001.

11. Yoshida T, Kinoshita H, Yoshida K, Mishima T, Yanishi M, Inui H, Komai Y, Sugi M, Inoue T, Murota T, Fukui K, Harada J, Kawa G, Matsuda T. Prognostic impact of perioperative lymphocyte-monocyte ratio in patients with bladder cancer undergoing radical cystectomy. Tumour Biol. 2016;37(8):10067-74.

12. Kwon BS, Jeong DH, Byun JM, Lee TH, Choi KU, Song YJ, Suh DS, Kim KH. Prognostic value of preoperative lymphocyte-monocyte ratio in patients with ovarian clear cell carcinoma. J Cancer. 2018;9(7):1127-34.

13. Białas AJ, Kornicki K, Ciebiada M, Antczak A, Sitarek P, MiłkowskaDymanowska J, Piotrowski WJ, Górski P. Monocyte to large platelet ratio as a diagnostic tool for pulmonary embolism in patients with acute exacerbation of chronic obstructive pulmonary disease. Pol Arch Intern Med. 2018;128(1):15-23.

14. Wang J, Gao K, Lei W, Dong L, Xuan Q, Feng M, Wang J, Ye X, Jin T, Zhang Z, Zhang Q. Lymphocyte-to-monocyte ratio is associated with prognosis of diffuse large B-cell lymphoma: correlation with CD163 positive M2 type tumor-associated macrophages, not PD-1 positive tumor-infiltrating lymphocytes. Oncotarget. 2017;8:5414-25.

15. Kumagai S, Tashima M, Fujikawa J, Iwasaki M, Iwamoto Y, Sueki Y, et al. Ratio of peripheral blood absolute lymphocyte count to absolute monocyte count at diagnosis is associated with progression-free survival in follicular lymphoma. Int J Hematol. 2014;99:737-42.

16. Wilcox RA, Ristow K, Habermann TM, Inwards DJ, Micallef IN, Johnston PB. The absolute monocyte and lymphocyte prognostic score predicts survival and identifies high risk patients in diffuse large B-cell lymphoma. Leukemia. 2011;25(9):1502-9.

17. Pereira A, Pereira JC, Martins S. Appendiceal neoplasms: diagnosis Management and Follow-up. Sci Med J. 2021;3(3):274-82.

18. Gajewski TF, Schreiber H, Fu YX. Innate and adaptive immune cells in the tumor microenvironment. Nat Immunol. 2013;14:1014-22.

19. Raina V, Singhal MK, Sharma A, Kumar L, Kumar R, Duttagupta S, Kumar B, Das P. Clinical characteristics, prognostic factors, and treatment outcomes of 139 patients of peripheral T-cell lymphomas from AllMS, New Delhi, India. J Clin Oncol. 2010;28:e18549-e18549.

20. Hasenclever D, Diehl V. A prognostic score for advanced Hodgkin's disease. International Prognostic Factors Project on Advanced Hodgkin's Disease. N Engl J Med. 1998;339:1506-14.

21. Noy R, Pollard JW. Tumor-associated macrophages: from mechanisms to therapy. Immunity. 2014;41:49-61.

22. Zhang Y, Zheng Y, Shou L, Shi Y, Shen H, Zhu M, Ye X, Jin J, Xie W. Increased serum level of interleukin-10 predicts poor survival and early recurrence in patients with peripheral T-cell lymphomas. Front Oncol. 2020:10:584261.

23. Reuter S, Lang D. Life span of monocytes and platelets: importance of interactions. Front Bioscie. 2009;14:2432-47.

24. Huang JJ, Li YJ, Xia Y, Wang Y, Wei WX, Zhu YJ. Prognostic significance of peripheral monocyte count in patients with extranodal natural killer/T cell lymphoma. BMC Cancer. 2013;13:222.

25. Mitrovic Z, Perry AM, Suzumiya J, Armitage JO, Au WY, Coiffier B, et al. The prognostic significance of lymphopenia in peripheral $T$ cell and natural killer $/ T$ cell lymphomas: a study of 826 cases from the International Peripheral T cell lymphoma project. Am J Hematol. 2012;87(8):790-4.

26. Porrata LF, Inwards DJ, Ansell SM, Micallef IN, Johnston PB, Hogan WJ, Markovic SN. Infused autograft lymphocyte-to-monocyte ratio and survival in T-cell lymphoma post autologous peripheral blood hematopoietic stem cell transplantation. J Hematol Oncol. 2015. https://doi.org/10. 1186/s13045-015-0178-5.

27. Feng $X Y, L i L$, Wu J, Zhang L, Sun ZC, Li X, Wang $X H$, Yu H, Chang Y, Wu XL, Zhou ZY, Wang GN, Li WC, Li ZM, Zhang XD, Zhang MZ. Complete blood count score model integrating reduced lymphocyte-monocyte ratio, elevated neutrophil-lymphocyte ratio, and elevated platelet-lymphocyte ratio predicts inferior clinical outcomes in adult T-lymphoblastic lymphoma. Oncologist. 2019;24(11):e1123-31. https://doi.org/10.1634/theon cologist. 
28. Ghosh S, TilakTVSVGK, Somasundaram V, Deepti M. The domino effecttreatment of superior vena cava obstruction triggering tumor lysis syndrome: a case report. SciMed J. 2021;3(1):44-50.

29. Harker LA, Roskos LK, Marzec UM, Carter RA, Cherry JK, Sundell B, Cheung EN, Terry D, Sheridan W. Effects of megakaryocyte growth and development factor on platelet production, platelet life span, and platelet function in healthy human volunteers. Blood. 2000;95:2514-22.

30. Plantureux L, Mège D, Crescence L, Dignat-George F, Dubois C, PanicotDubois L. Impacts of cancer on platelet production, activation and education and mechanisms of cancer-associated thrombosis. Cancers. 2018;10:441.

31. Semple JW, Italiano JE Jr, Freedman J. Platelets and the immune continuum. Nat Rev Immunol. 2011;11:264-74.

32. Kasper B, Brandt E, Brandau S, Petersen F. Platelet factor 4 (CXC chemokine ligand 4) differentially regulates respiratory burst, survival, and cytokine expression of human monocytes by using distinct signaling pathways. J Immunol. 2007;179:2584-91.

33. Soga F, Katoh N, Inoue T, Kishimoto S. Serotonin activates human monocytes and prevents apoptosis. J Invest Dermatol. 2007;127:1947-55.

34. Rothwell PM, Wilson M, Price JF, Belch JF, Meade TW, Mehta Z. Effect of daily aspirin on risk of cancer metastasis: Astudy of incident cancers during randomised controlled trials. Lancet. 2012;379:1591-601.

35. Eriksson O, Mohlin C, Nilsson B, Ekdahl KN. The human platelet as an innate immune cell: interactions between activated platelets and the complement system. Front Immunol. 2019;10:1590.

36. Mihong Choi, Jeong-Ok Lee, Jongheon Jung, Ji Yun Lee, Eunyoung Lee, Hyewon Lee, Soo-Mee Bang, Hyeon Seok Eom, Jong Seok Lee. Prognostic value of platelet count in patients with peripheral T cell lymphoma. Acta Haematol. 2019;141(3):176-186.

37. Guillem-Llobat P, Dovizio M, Bruno A, Ricciotti E, Cufino V, Sacco A, Grande R, Alberti S, Arena V, Cirillo M, et al. Aspirin prevents colorectal cancer metastasis in mice by splitting the crosstalk between platelets and tumor cells. Oncotarget. 2016;7:32462-77.
38. Tamar Tadmor, MD; Alessia Bari, MD; Luigi Marcheselli, MS; Stefano Sacchi, MD;Ariel Aviv, MD; Luca Baldini, MD; Paolo G. Gobbi, MD; Samantha Pozzi, MD;Paola Ferri, MS; Maria Christina Cox, MD; Nicola Cascavilla, MD;Emilio Iannitto, MD; Massimo Federico, MD; and Aaron Polliack, MD.Absolute Monocyte Count and Lymphocyte-Monocyte Ratio Predict Outcome in Nodular Sclerosis Hodgkin Lymphoma: Evaluation Based on Data From 1450 Patients. Mayo Clin Proc. June 2015;90(6):756-764, doi.org/https:// doi.org/10.1016/j.mayocp.2015.03.025

39. Dosani T, Covut F, Beck R, Driscoll JJ, de Lima M, Malek E. Significance of the absolute lymphocyte/monocyte ratio as a prognostic immune biomarker in newly diagnosed multiple myeloma. Blood Cancer J. 2017;7: e579. https://doi.org/10.1038/bcj.2017.60.

40. Porrata LF, Inwards DJ, Ansell SM, Micallef IN, Johnston PB, Hogan WJ, Markovic SN. Infused Autograft Lymphocyte to Monocyte Ratio and Survival in Diffuse Large B Cell Lymphoma. Biol Blood Marrow Transplant. 2014;20:1804-12.

41. Luo HC, He LB, Zhang GJ, Yu JH, Chen YP, Yin HL, Goyal H, Zhang GM, Xiao YX, Gu CG, Yin MG, Jiang XC, Song XY, Zhang L. Normal Reference Intervals of Neutrophil-To-Lymphocyte Ratio, Platelet-To-Lymphocyte Ratio, Lymphocyte-To-Monocyte Ratio, and Systemic Immune Inflammation Index in Healthy Adults: a Large Multi-Center Study from Western China. Clin Lab. 2019;65:255-65.

42. Kheradmand M, Hedayatizadeh-Omran A, Shamshirian A, Barzegar A. Normal values of neutrophil-to-lymphocyte ratio, lymphocyte-to-monocyte ratio and platelet-to-lymphocyte ratio among Iranian population: results of Tabari cohort. Caspian J Intern Med. 2019;10(3):320-5.

\section{Publisher's Note}

Springer Nature remains neutral with regard to jurisdictional claims in published maps and institutional affiliations.
Ready to submit your research? Choose BMC and benefit from:

- fast, convenient online submission

- thorough peer review by experienced researchers in your field

- rapid publication on acceptance

- support for research data, including large and complex data types

- gold Open Access which fosters wider collaboration and increased citations

- maximum visibility for your research: over $100 \mathrm{M}$ website views per year

At BMC, research is always in progress.

Learn more biomedcentral.com/submissions 